\title{
Relationship Between QRS Duration on ECG and LV Systolic Function by Echocardiography in Patients with STEMI
}

\author{
MD. BILLAL HOSSAIN ${ }^{1}$, MSI TIPU CHOWDHURY ${ }^{2}$, MD. ZAHIDUL ISLAM ${ }^{1}$, RAKHAL CHANDRA DEBNATH ${ }^{1}$, \\ SAJAL KRISHNA BANERJEE ${ }^{2}$, M. SAIFUL BARI ${ }^{1}$ \\ ${ }^{1}$ Department of Cardiology, Mymesingh Medical College Hospital, Mymensingh, ${ }^{2}$ Department of Cardiology, Bangabandhu \\ Sheikh Mujib Medical University, Dhaka. \\ Address of Correspondence: Dr. Md. Billal Hossain, Resident, Department of Cardiology, Mymensingh Medical College \\ Hospital, Mymensingh. Email: dr.billalcardio@gmail.com
}

\begin{abstract}
:
Background: Acute STEMI patients constitute a large proportion of admissions in coronary care unit and their management and prognostic implification is of immense importance. Prolonged QRS duration on electrocardiogram (ECG) has been associated with cardiac structural and functional abnormalitiesVery few studies were performed correlating QRS duration and LV systolic function in acute STEMI patients in our country. This study assessed whether QRS duration on ECG is correlated with LV systolic function measured in patients with acute STEMI.

Aim of the Study: The aim of the study is to evaluate the relationship between QRS duration on ECG with left ventricular systolic function by echocardiography in patients with acute ST elevation myocardial infarction. Methods: A cross sectional observational study was conducted in the department of Cardiology in Mymensingh Medical College Hospital from November, 2016 to February, 2018 among purposively selected 235 patients with STEMI following inclusion \& exclusion criteria. After detailed history, physical examination and investigations the selected patients underwent transthoracic Echocardiography to asses left ventricular systolic

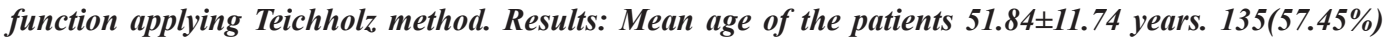
patients had acute anterior MI, while 98(41.70\%) had Inferior MI and only 2(0.85\%) had lateral MI. Mean QRS duration was $93.3 \pm 10.18 \mathrm{~ms}$, with maximum value $125 \mathrm{~ms}$ and minimum value $66 \mathrm{~ms}$. Mean left ventricular ejection fraction was $49.71 \% \pm 9.87 \%$, with maximum value $74 \%$ and minimum value $23 \%$. QRS duration and left ventricular ejection fraction were moderate negative correlation with $r=-0.611,<P=0.001$. Conclusion: The study concluded that QRS duration is negatively correlated with Left ventricular systolic function in patients with acute ST elevation myocardial infarction.
\end{abstract}

Key words: ST elevation myocardial infarction (STEMI), QRS duration, Left ventricular ejection fraction $(L V E F)$.

University Heart Journal 2019; 15(2): 54-59

Introduction:

Cardiovascular disease (CVD) is known to be the leading cause of death worldwide. In 2015, 19.9 million CVD deaths occurred (one-third of all global deaths), and 423 million people had prevalent CVD (1 in 17 of the global population). ${ }^{1}$

Despite decreasing mortality trends of coronary artery disease (CAD) in many developed countries, increasing number is noticed in developing countries. ${ }^{2}$ Between 1990 and 2015, estimated age-standardized CVD mortality remained relatively stable in Sub- Saharan Africa and Southeast Asia, and increased in Bangladesh and the Philippines. ${ }^{1}$
More recent data indicates CAD prevalence between $3.4 \%{ }^{3}$ in rural and $19.6 \%$ in an urban sample of working professionals. $^{4}$

MI is one of the five main manifestations of coronary heart disease, namely stable angina pectoris, unstable angina pectoris, MI, heart failure and sudden death. ${ }^{5}$

Acute myocardial infarction appeared as the top leading cause(3.7\%) of deaths across 504 public hospitals in Bangladesh in 2012 as reported by the "Health Bulletin 2013. ${ }^{6}$

The electrocardiogram, due to its wide availability, low cost and simplicity, is an essential tool for the diagnosis 
and prognostic stratification of ST-segment elevation cute coronary syndrome (STEACS). ${ }^{7}$

Prolonged QRS duration can lead to ventricular dysfunction in long term and also it can be a direct result of ventricular dysfunction. Additionally, it was found that prolonged QRS duration was related to poor prognosis in AMI. ${ }^{8}$

Another study showed that patients with prolongation of QRS duration had increased ventricular volumes, decreased left ventricular EF, and higher incidence of sudden cardiac death. ${ }^{9}$

To systematically study this association, we correlated QRS duration with resting LV ejection fraction (EF) as obtained by Echocardiography in patients with STEMI. It would be clinically useful and cost effective if the standard 12 lead ECG could be used to predict LV systolic function following acute ST elevation myocardial infarction.

\section{Methods: :}

This was a cross sectional observational study conducted in the department of Cardiology in Mymensingh Medical College Hospital, Mymensingh from November, 2016 to February, 2018 among purposively selected 235 patients with STEMI following inclusion \& exclusion criteria.

\section{Patients}

Patients admitted in the CCU of Mymensingh Medical College Hospital, Mymensingh with first attack of acute ST elevation MI who fulfill the inclusion criteria. Patients having previous history of MI, Patient with known non ischaemic cause of prolonged QRS duration(WPW syndrome, hyperkalemia etc),patient with typical left or right bundle branch block,pacemaker rhythm,Arrhythmia and patients with antiarrhythmic drugs, Patients with known valvular heart disease, congenital heart disease and cardiomyopathy, Any systemic infection. Patients with non ischaemic causes of ST elevation (early repolarization syndrome, Brugada syndrome, acute paricarditis, hyperkalemia etc) were excluded from the study.

\section{ECG(QRS duration)}

Standard 12-lead ECG with a paper speed of $25 \mathrm{~mm} / \mathrm{s}$ and amplification of $10 \mathrm{~mm} / \mathrm{mV}$ of each patient will be obtained on admission and before discharge. The QRS interval is measured from the beginning of the first appearing $\mathrm{Q}$ or $\mathrm{R}$ wave to the end of the last appearing R,S,R', or S' wave . QRS duration is usually 0.06 to 0.10 seconds. ${ }^{10}$ QRS duration on each ECG done by computer(electronic) measurements which manually confirmed with the help of a caliper and magnifying lens. Means of 2 or 3 beats are calculated and the mean value for QRS duration in infarctrelated leads are computed.

\section{Echocardiography}

Left ventricular ejection fraction were calculated( by TOSHIBA, ISTYLE, Xario-2010) at 2D \& Mode mode echocardiography with cursor placed perpendicular to LAX of LV at the tip of the mitral valve in a parasternal LAX view with TTE.Another measurements taken parasternal SAX view with currsor placed through the cavity of the LV at base, mid \& apical region. LVEF measured by Teichholz method and findings of all readings were averaged.

\section{Statistical analysis}

Data analysis was conducted with SPSS 20.0

(Statistical Package for Social Sciences version 20) for windows software.Continuous parameters were expressed as mean $\pm \mathrm{SD}$ and categorical parameters as percentage. Student's $t$ test was used for the continuous variables whereas Chi-square $\left(C^{2}\right)$ test was used to express association between categorical variables. Comparison between groups was done by unpaired t-test.Correlation was done by using Pearson's correlation coefficient test. Multiple logistics regression analysis was done to find out association of risk factors and QRS duration with LV systolic function. In all cases, P-value of $<0.05$ was considered as significant.

\section{Results:}

The findings of the study has been described as follows: Regarding age of the patients, it was observed that majority (57.04\%) of patients in between 45-65 years of age Maximum age of the respondents was 82 years and minimum age was 18 years Mean was $51.84 \pm 11.74$ years. (Table I).

Table-I

Age distribution of the study patients

\begin{tabular}{lcc}
\hline Age in Years & Frequency & Percentage \\
\hline $15-24$ & 1 & $0.43 \%$ \\
$25-34$ & 13 & $5.53 \%$ \\
$35-44$ & 42 & $17.87 \%$ \\
$45-54$ & 70 & $29.79 \%$ \\
$55-64$ & 64 & $27.23 \%$ \\
$65-74$ & 40 & $17.02 \%$ \\
\hline
\end{tabular}

Mean $=51.84 \pm 11.74$ years. 
With regard to sex of the respondents, it was found that highest majority $215(91.49 \%)$ of the respondents were males, whereas only $20(8.51 \%$ ) were females.(Figure 1 )

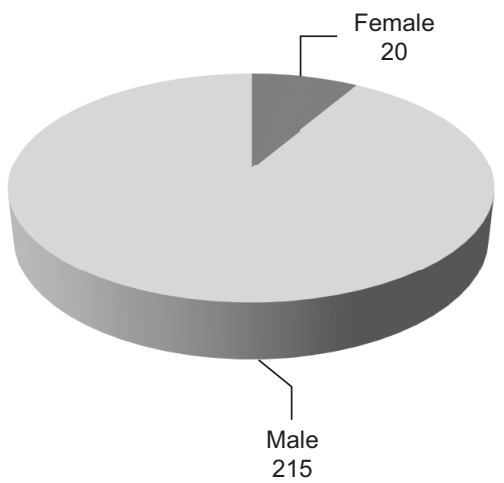

Fig.-1: Sex distribution of the study patients.

Among 235 study patients 177 (75.31\%) have history of smoking, 94 (40\%) have history of hypertension, 38 (16.17\%) have history of DM, 126 (53.61\%) have history of dyslipidemia, 22(9.36\%) have Family History of IHD. (Figure:2)

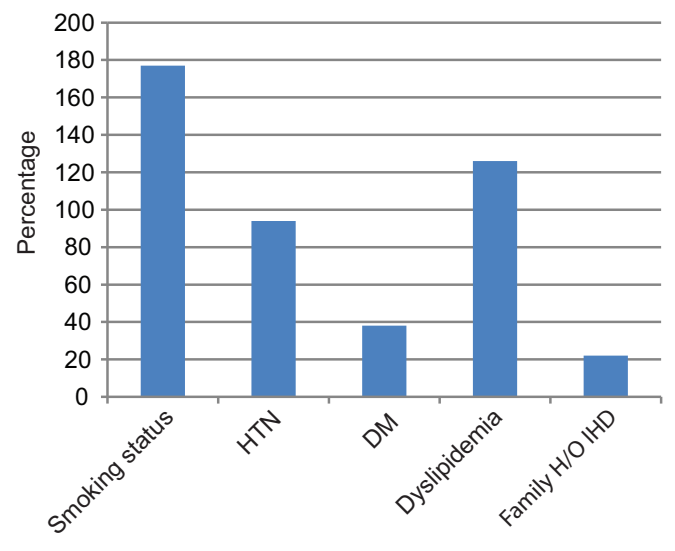

Risk factors

Fig.-2: Risk Factors Distribution of the study population

With regard to type of Myocardial Infarction by which the respondents were affected, it was revealed that highest 98(41.70\%) patients had Inferior MI, while $84(35.75 \%)$ had Anterior MI, 51(21.70\%) had extensive anterior MI and only $2(0.85 \%)$ had lateral MI. (Table: II)

Table-II

Respondents by type of Acute STEMI

\begin{tabular}{lcc}
\hline Type of MI & Frequency & Percentage \\
\hline Inferior & 98 & $41.70 \%$ \\
Anterior & 84 & $35.75 \%$ \\
Extensive Anterior & 51 & $21.70 \%$ \\
\hline
\end{tabular}

The patients were categorized into six groups on the basis of QRS duration like $\geq 80 \mathrm{~ms}, 81-90 \mathrm{~ms}, 91-100 \mathrm{~ms}, 101-110$ $\mathrm{ms}, 111-120 \mathrm{~ms}$ and $>120 \mathrm{~ms}$ and their relationship were evaluated by normal (LVEF $\geq 55 \%$ ) \& abnormal (LVEF $<55 \%$ ) LV systolic function. 35 patients had QRSd $\leq 80 \mathrm{~ms}$, of them 32 (91.47\%) had LVEF $\geq 55 \%$ and $3(8.57 \%)$ had LVEF $<55 \%$. 57 patients had QRSd $81-90 \mathrm{~ms}$, of them $23(40.35 \%)$ had LVEF $\geq 55 \%$ and $34(59.65 \%)$ had LVEF $<55 \%$. 89 patients had QRSd $91-100 \mathrm{~ms}$, of them $17(19.10 \%)$ had LVEF $\geq 55 \%$ and 72 (80.90\%) had LVEF $<55 \% .42$ patients had QRSd 101-110 ms, of them $3(7.14 \%)$ had LVEF $\geq 55 \%$ where as $39(92.86 \%)$ had LVEF $<55 \%$. 11 patients had 111-120 ms, of them 3(27.27\%) had LVEF of $\geq 55 \%$ and $8(72.73 \%)$ had LVEF $<55 \%$. Only 1 patient had QRSd $>120$ ms with LVEF $<55 \%$. The difference was statistically significancant $(\mathrm{p}<0.001)$ (Table:III)

\section{Table-III}

Deferent level of QRSd duration with Left Ventricular Systolic function (LVEF)

\begin{tabular}{lccc}
\hline $\begin{array}{l}\text { QRS Duration } \\
\text { in ms }\end{array}$ & Total & \multicolumn{2}{c}{$\begin{array}{r}\text { Left Ventricular Ejection } \\
\text { Fraction (LVEF) }\end{array}$} \\
\cline { 2 - 4 } & & $\geq 55 \%$ & $<55 \%$ \\
\hline$\leq 80$ & 35 & $32(91.47 \%)$ & $3(8.57 \%)$ \\
$81-90$ & 57 & $23(40.35 \%)$ & $34(59.65 \%)$ \\
$91-100$ & 89 & $17(19.10 \%)$ & $72(80.90 \%)$ \\
$101-110$ & 42 & $3(7.14 \%)$ & $39(92.86 \%)$ \\
$111-120$ & 11 & $3(27.27 \%)$ & $8(72.73 \%)$ \\
$>120$ & 1 & $0(0 \%)$ & $1(100.00 \%)$ \\
\hline Total & 235 & 78 & 157 \\
\hline
\end{tabular}

(a) Chi-Squared test $=95.448, \mathrm{df}=3 ; \mathrm{p}=<0.001$

Mean QRS durations were calculated for normal LV systolic function to severe LV systolic dysfunction. With LVEF $\geq 55 \%, 45-54 \%, 30-44 \%$ and $<30 \%$ mean QRSd(ms) was $84.54 \pm 10.49,92.76 \pm 7.15,100.94 \pm 7.13$ and $111.00 \pm 14.16$ respectively. i.e. increased mean QRSd with increased severity of LV systolic dysfunction was found. (Table: IV)

\section{Table-IV}

Mean QRS duration in the patients group with a different level of Left Ventricular Systolic functions (LVEF): From normal function to Severe LV Systolic dysfunction.

\begin{tabular}{lcccc}
\hline QRSd(ms) & \multicolumn{4}{c}{ LVEF } \\
\cline { 2 - 5 } & $>55 \%$ & $45-54 \%$ & $30-44 \%$ & $<30 \%$ \\
\hline $\mathrm{N}$ & 78 & 82 & 71 & 4 \\
$\mathrm{X}($ Mean) & 85.54 & 92.76 & 100.94 & 111.00 \\
$\mathrm{SD}$ & 10.49 & 7.15 & 7.13 & 14.16 \\
\hline \multirow{2}{*}{ Mean QRS durations were calculated for normal LV systolic } \\
function to severe LV systolic dysfunction. With LVEF
\end{tabular}


$\geq 55 \%, 45-54 \%, 30-44 \%$ and $<30 \%$ mean $\mathrm{QRSd}(\mathrm{ms})$ was $84.54 \pm 10.49,92.76 \pm 7.15,100.94 \pm 7.13$ and $111.00 \pm 14.16$ respectively. i.e. increased mean QRSd with increased severity of LV systolic dysfunction was found. (Table: IV).

\section{Table-IV}

Mean QRS duration in the patients group with a different level of Left Ventricular Systolic functions (LVEF): From normal function to Severe LV Systolic dysfunction.

\begin{tabular}{lcccc}
\hline QRSd(ms) & \multicolumn{4}{c}{ LVEF } \\
& $>55 \%$ & $45-54 \%$ & $30-44 \%$ & $<30 \%$ \\
\hline $\mathrm{N}$ & 78 & 82 & 71 & 4 \\
$\mathrm{X}$ (Mean) & 85.54 & 92.76 & 100.94 & 111.00 \\
$\mathrm{SD}$ & 10.49 & 7.15 & 7.13 & 14.16 \\
\hline
\end{tabular}

Mean LVEF was $53.20 \pm 8.38(\%)$ in patients with normal QRS(QRSd < $100 \mathrm{~ms})$ whereas mean LVEF was $42.95 \pm 9.02(\%)$ in patients with prolong QRS (QRSd $>100 \mathrm{~ms}$ )). This was statistically significant (P-value $<0.001$ ) (Table:V)
Scatter diagram showing Correlation between QRS duration and Left Ventricular Ejection Fraction (LVEF) of the study population.(Figure:3)

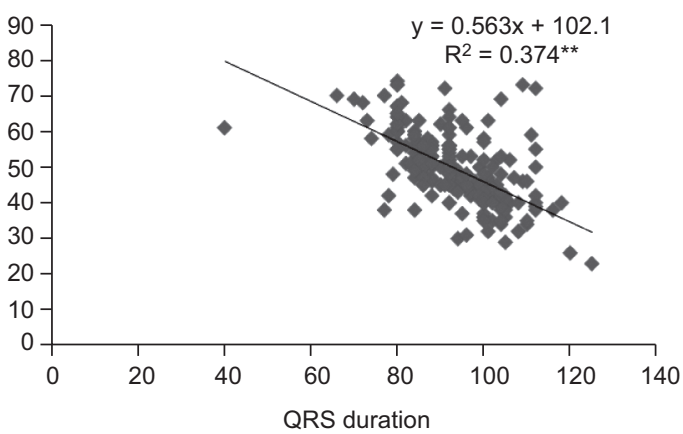

Fig.-3:

By multiple regression analysis it was found that the dependent variable LVEF (\%) significantly influenced by independent variable QRS duration. Positively Change of QRS duration with negatively change of LVEF (\%) significantly (Table:VI).

Table-V

Mean LVEF in patients with QRSd <100ms and QRSd>100 ms

\begin{tabular}{lccc}
\hline Parameters & QRSd & QRSd $>$ & p-value \\
& $\begin{array}{c}\leq 100 \mathrm{~ms} \\
(\text { Mean } \pm \text { SD) }\end{array}$ & $100 \mathrm{~ms}$ & \\
\hline EF & $53.20 \pm 8.38$ & $42.95 \pm 9.02$ & $<0.001$ \\
\hline
\end{tabular}

QRS duration showed a moderate negative correlation $(\mathrm{r}=-0.611)$ with left Ventricular Ejection Fraction (LVEF) which is statistically significanct $(\mathrm{p}<0.001)$.

Table-VI

Multiple Regression Analysis of study population

\begin{tabular}{|c|c|c|c|c|c|c|c|}
\hline \multirow[t]{2}{*}{ Model } & \multirow{2}{*}{$\begin{array}{c}\text { Unstandardized } \\
\text { Coefficients } \\
\text { B }\end{array}$} & \multicolumn{2}{|c|}{$\begin{array}{l}\text { Standardized } \\
\text { Coefficients }\end{array}$} & \multirow[t]{2}{*}{$\mathrm{T}$} & \multirow[t]{2}{*}{$\begin{array}{l}\text { P Value \& } \\
\text { Sig. Level }\end{array}$} & \multicolumn{2}{|c|}{$\begin{array}{c}95.0 \% \text { Confidence } \\
\text { Interval for B }\end{array}$} \\
\hline & & Std. Error & Beta & & & Lower Bound & Upper Bound \\
\hline$\overline{\text { (Constant) }}$ & 113.135 & 7.713 & & 14.669 & 0.000 & 97.937 & 128.333 \\
\hline Age & .003 & .047 & .003 & .053 & $0.957 \mathrm{NS}$ & -.090 & .095 \\
\hline Sex & .678 & 2.109 & .019 & .321 & $0.748 \mathrm{NS}$ & -3.478 & 4.833 \\
\hline Smoking status & .428 & 1.426 & .019 & .300 & $0.765 \mathrm{NS}$ & -2.382 & 3.237 \\
\hline HTN & -2.968 & 1.078 & -.148 & -2.753 & $0.07 \mathrm{NS}$ & -5.093 & -.843 \\
\hline DM & .768 & 1.416 & .029 & .542 & $0.588 \mathrm{NS}$ & -2.023 & 3.558 \\
\hline Dyslipidemia & -.789 & 1.039 & -.040 & -.759 & $0.449 \mathrm{NS}$ & -2.837 & 1.259 \\
\hline Family H/O IHD & -3.317 & 1.831 & -.098 & -1.811 & $0.081 \mathrm{NS}$ & -6.925 & .291 \\
\hline QRSd & -.580 & .048 & -.630 & -12.099 & $0.001 \mathrm{~S}$ & -.674 & -.485 \\
\hline
\end{tabular}




\section{Discussion:}

A cross sectional observational study was conducted at Mymensingh Medical College Hospital, Mymensingh among purposively selected 235 patients with Acute ST Elevation Myocardial Infarction from November 2016 to February 2018 to assess relationship between QRS duration on ECG with Left Ventricular systolic function by Echocardiography.

Mean age of patients was $51.84 \pm 11.74$ years and majority of patients 134 (57.02\%) were in between 46-65 years of age. Majority 215(91.49\%) of the respondents were males and $8.51 \%$ of our study population were female with male female ratio was 12.5:1 177(75.31\%) were smokers, $94(40.00 \%)$ respondents had history of hypertension, 38 (16.17\%) of patients had history of Diabetes Mellitus. 135(57.45\%) had acute anterior ST Elevation Myocardial Infarction (including extensive anterior and anterosepal myocardial infarction), while $98(41.70 \%)$ patients had Inferior MI and only $2(0.85 \%)$ had lateral MI.

The patients were categorized into six groups on the basis of QRS duration like $\geq 80 \mathrm{~ms}, 81-90 \mathrm{~ms}, 91-100 \mathrm{~ms}, 101$ $110 \mathrm{~ms}, 111-120 \mathrm{~ms}$ and $>120 \mathrm{~ms}$ and their relationship were evaluated by normal ( LVEF $\geq 55 \%$ ) \& abnormal( LVEF $<55 \%$ ) LV systolic function. 35 patients had QRSd $\leq 80 \mathrm{~ms}$, of them $32(91.47 \%)$ had LVEF $\geq 55 \%$ and $3(8.57 \%)$ had LVEF $<55 \%$. 57 patients had QRSd $81-90 \mathrm{~ms}$, of them $23(40.35 \%)$ had LVEF $\geq 55 \%$ and $34(59.65 \%)$ had LVEF $<55 \% .89$ patients had QRSd $91-100 \mathrm{~ms}$, of them $17(19.10 \%)$ had LVEF $\geq 55 \%$ and $72(80.90 \%)$ had LVEF $<55 \% .42$ patients had QRSd 101-110 ms, of them 3(7.14\%) had LVEF $\geq 55 \%$ whereas $39(92.86 \%)$ had LVEF $<55 \%$. 11 patients had $111-120 \mathrm{~ms}$, of them $3(27.27 \%)$ had LVEF of $\geq 55 \%$ and $8(72.73 \%)$ had LVEF $<55 \%$. Only 1 patient had QRSd $>120$ ms with LVEF $<55 \%$. The difference was statistically significancant $(\mathrm{p}<0.001)$

Murkofsky et al. studied 270 patients referred for a radionuclide ventriculography to ascertain if prolonged QRS duration was associated with left ventricular dysfunction. They found that a QRS duration of more than $100 \mathrm{~ms}$ was highly specific ( $83.6 \%$ ) but only moderately sensitive (43.8\%) for predicting an abnormal EF. The QRS duration in patients with an abnormal EF was significantly longer compared with that in patients with normal $\mathrm{EF}(\mathrm{p}=$ 0.0001). ${ }^{11}$

Mean QRS durations of the study patients were calculated for normal LV systolic function to severe LV systolic dysfunction. With LVEF $\geq 55 \%, 45-54 \%, 30-44 \%$ and $<30 \%$ mean QRSd(ms) was $84.54 \pm 10.49,92.76 \pm 7.15,100.94 \pm 7.13$ and $111.00 \pm 14.16$ respectively.
Mean LVEF was 53.20 \pm 8.38 (\%) in patients with normal QRS durations ( $\mathrm{QRSd}<100 \mathrm{~ms}$ ) where as mean LVEF was 42.95 \pm 9.02 (\%) in patients with prolong QRS durations $(\mathrm{QRSd}>100 \mathrm{~ms})$ ). It was statistically significant (P-value $<0.001)$.

Pearson correlation coefficient test by scatterred diagram showed QRS duration was moderately negative correlation $(\mathrm{r}=-0.611)$ with left Ventricular Ejection Fraction (LVEF) which was also statistically significant $(\mathrm{p}<0.001)$.

Mezue et al. Found a negative correlation was between QRS duration and LVEF on admission $(r=" 0.25 ; \mathrm{p}=0.01)$, with an even stronger correlation after discharge $(r=$ " 0.30 ; $\mathrm{p}=0.01$ ) When subdivided into QRS durations $<110$ milliseconds (ms) and $\geq 110 \mathrm{~ms}, \mathrm{QRS} \geq 110 \mathrm{~ms}(\mathrm{n}=22)$ was associated with a lower LVEF on admission ( $32 \pm 13 \%$ vs. $43 \pm 14 \% ; \mathrm{p}<0.01)$ and at post-discharge follow-up $(31 \pm$ $16 \%$ vs $45 \pm 15 \%$; p b 0.01 ) when compared to QRS $<110$ $\mathrm{ms}(\mathrm{n}=108)$ following acute STEMI. ${ }^{12}$

Multiple regression analysis of this study found that the depended variable LVEF (\%) significantly influenced by independent variable QRS duration. Positively Change QRS duration with negatively change of LVEF (\%) significantly.

Mezue et al. Showed after multivariate regression analysis, QRS duration was a statistically significant predictor of post discharge LVEF $(\mathrm{p}=0.024$, regression coefficient= “ 0.166$)^{12}$

Patwary et al. showed Prolonged QRS duration of AMI patient indicates left ventricular systolic dysfunction. ${ }^{13}$

This study done on first attack of acute STEMI and it was found that ORS duration on ECG was negatively correlated with left ventricular ejection fraction which was synonymous with other studies.

\section{Conclusion:}

QRS duration has moderate negative correlation with left Ventricular Ejection Fraction (LVEF) assessed by echocardiography following acute ST elevation myocardial infarction. Acute anterior(including extensive anterior and anteroseptal) ST elevation myocardial infarction is more common type of Myocardial infarction.

\section{Limitations of The Study:}

The limitations of the study were as follows:

- The sample size was small and study period was short.

- This study was conducted in only one center (Department of Cardiology, Mymensingh Medical 
College Hospital) and majority of the study population were male. Thus, these results need to be re-evaluated in other health care center by inclusion of male and female in large numbers.

- Left ventricular systolic function only measured by 2D \& M Mode transthoracic Echocardioagraphy applying Teichholz methods. Simpson's method \& other advanced methods of Echocardiography to measure LV systolic function was not applied.

\section{Recommendations:}

The study recommends that treatment strategy and closer surveillance should be offered to acute ST elevation myocardial infarction patients with prolong QRS duration, as these patients has poor left ventricular systolic function.

The result of this study needs further confirmation in a randomized large scale, multicentre prospective cohort study.

\section{References:}

1. Roth GA, Johnson C, Abajobir A et al. Global, regional, and national burden of cardiovascular diseases for 10 causes, 1990 to 2015. J Am Coll Cardiol 2017;70:1-25

2. Bhatnagar P, Wickramasinghe K, Williams J Rayner M. and Townsend N. 'The epidemiology of cardiovascular disease in the UK. Heart 2015;101(15):1182-9

3. Zaman M.M, Ahmed JU, Chowdhury SR, Numan SM, Parvin K, Islam M.S. 'Prevalence of Ischaemic Heart Disease in a Rural Population of Bangladesh. Indian Heart Journal 2007; 59(3):316- 22 .

4. Ahsan S, Haque KMHS, Salman M. Detection of ischaemic heart disease with risk factors in different categories of employees of University Grants Commission. Univ Heart J $2009 ; 5: 20-3$

5. Mendis S, Thygesen K, Kuulasmaa K, Giampoli S, Mähönen $\mathrm{M}$, Blackett KN, et al. World Health Organization definition of myocardial infarction: 2008-09 revision. Int J Epidemiol 2011; 40:139-46.

6. Mamun MA, Azad MC, Shana N, Zaman MM. Emerging Burden of Cardiovascular Disease in Bangladesh. Journal of Atherosclerosis and Thrombosis 2015; 22:1-11.

7. Brignole $\mathrm{M}$, Auricchio A, Barón-Esquivias G, Bor-dachar P, Boriani G, Breithardt OA, et al. Guía de práctica clínica de la ESC 2013 sobre estimulación cardiaca y terapia de resincronización cardiaca. Rev Esp Cardiol 2014; 67(1):58.1-60.

8. Acil T, Türkoz R, Acil M. Value of prolonged QRS duration as a predictor of low cardiac output syndrome in patients with impaired left ventricular systolic function who undergo isolated coronary artery bypass grafting. Am J Cardiol 2006;98:1357-1362

9. Yerra L, Anavekar N, Skali H. Association of QRS duration and outcomes after myocardial infarction: the VALIANT trial. Heart Rhythm 2006;3:313-6.

10. Rumulo F. Basic and Bedside Electrocardiography. New Delhi: Replika Press; 2010. P.10-11

11. Murkofsky R.L, Dangas G, Diamond JA, Mehta, DA. Schaffer, J.A., Ambrose, A prolonged QRS duration on surface electrocardiogram is a specific indicator of leftventricular dysfunction, J. Am. Coll. Cardiol 1998; 32(2):476-82.

12. Maludum O, Nwakile C, Mezue K, Shah M, Purushottam B, Morris DL, et al. QRS duration predicts left ventricular systolic function following STelevation myocardial infarction. International Journal of Cardiology 2016; 207:300-2

13. Patwary M.S.R, Reza A.Q.M., Mohibullah, A.K.M. Prolonged QRS duration of AMI patients indicative of left ventricular systolic dysfunction. Chest and Heart journal 2008; 31:36-9. 